\title{
Teaching chemistry through music in elementary schools
}

\author{
Kama Illias
}

Gothic College of Teachers Education, Department of Art and craf, Bonga Gufuiet, Ethiopia

Email address:

kamame2012@gmail.com (K. Illias)

To cite this article:

Kama Illias. Teaching Chemistry through Music in Elementary Schools. International Journal of Computational and Theoretical Chemistry. Vol. 2, No. 1, 2014, pp. 1-13. doi: 10.11648/j.ijctc.20140201.11

\begin{abstract}
Kama Illias. Chemistry to Music: Discovering how Music-Based Teaching Affects Academic Achievement and Student Motivation in an 8th Grade Science Class in Gotico Elementary school. Teachers should have access to new and innovative tools in order to engage and motivate their students in the classroom. This is especially important as many students view school as an antiquated and dull environment - which they must seemingly suffer through to advance. School need not be a dreaded environment. The use of music as a tool for learning can be employed by any teacher to create an engaging and exciting atmosphere whose students actively participate and learn to value their classroom experience. Through this study, product and process was developed that is now available for any 8th grade science teacher interested in using music to enhance their content. In this study 8th grade students $(n=41)$ in public school classroom actively interacted with modern songs created to enhance the teaching of chemistry. Data were collected and analyzed in order to determine the effects that the music treatment had on student achievement and motivation, compared to a control group $(\mathrm{n}=35)$. Current literature provides a foundation for the benefits for music listening and training, but academic research in the area of using music as a tool for teaching content was noticeably absent. This study identifies a new area of research called "Music-based Teaching" which results in increases in motivation for 8th grade students learning chemistry. The unintended results of the study are additionally significant as the teacher conducting the treatment experienced newfound enthusiasm, passion, and excitement for his profession. Chemistry to Music: Discovering How Music-Based Teaching Affects Academic Achievement and Student Motivation in an 8th Grade Science Class in Gotico Elementary school.
\end{abstract}

Keywords: Chemistry, Music, Experiment, SelfEsteem, Motivation

\section{Introduction}

Individuals are the main source of improvement of the society and sustainability of its presence if they grown up appropriately. Education being a bridge between human and the life is impressed and shaped by the developments of era, so education of individuals become important parallel with the progress and changes in the society.

Teachers should plan science education with respect to their students. For a qualified science education, the curriculum should be planned according to the interests of students. It does not only motivate students but also make them learn the subject in an effective way. According to Collette and Chapatti (1994), science education should be related with the attitudes and interests of the students. These psychological concepts help motivate students and make the educational process more pertinent. Bybee (1993), also agree that curriculum and instruction should be integrated with the interests and ethical backgrounds of the students. They should guide learning toward understanding and fulfilling basic human needs and facilitating personal development; maintaining and improving the physical environment; conserving natural resources so they are used wisely; and developing and understanding the interdependence among people at local, national and global levels- that is a sense of community.

From the extensive literature, it is obvious that students will learn better if they actively participate in educational process. According to Sanfeliz and Stalzer (2003), one way to help students become active agents in their society is by making the educational experience more pertinent, especially regarding science. Students can be motivated to learn a scientific concept and discover the importance that such experience has to offer. If the student has the chance to learn what they find interesting in science, children will feel a sense of control and greater responsibility and enthusiasm toward their learning.

Chemistry is an important subject as a branch of science. The world is filled with the products of chemical studies. The basis of all chemical studies starts with chemistry 
education. Dori and Hamairi (2003) claim that chemical education is a complex human endeavor which involves deep understanding of diverse concepts and requires a mental transfer between several modes of representation. According to Gregory and Richard (2002), chemistry learning involves establishing conceptual relationship among macroscopic, microscopic, and symbolic representations.

This study informs the existing literature by implementing an innovative use of music and by testing its effects on academic achievement and motivation. Assumptions and Rationale for Study This study was motivated by a commitment to developing innovative music-based teaching tools for educators in order to help them engage and motivate their students. One of the study's major goals was to examine and discuss how music can be used in a middle grades classroom to motivate students and increase academic achievement. As a former teacher I had implemented this pedagogical strategy and wanted to test its portability. This fore, I initiated the study assuming that any teacher could implement a music-based lesson and have a successful experience with his/his students regardless of grade level, content area, or musical ability. Accordingly, I chose to look at 8 th grade science, a grade level and subject matter most foreign to my experience.

\subsection{Purpose}

The purpose of this study was to determine the effects of using original music teaching chemistry to 8th grade science students. The treatment was implemented in two $8^{\text {th }}$ grade science classes; two additional classes were used as the control group for the study. The study relied on mixed methods for investigating the effect this music-based teaching had on students' motivation and academic achievement. Ultimately, the findings of this study will be used to critically analyze this method of teaching so that either research can be conducted around this teaching process and accompanying curriculum.

\subsection{Research Questions}

This study addressed two research questions:

1. Does music-based teaching increase academic achievement in science?

2. How does music-based teaching affect student motivation for learning science?

The first question involves the use of an in-class test/retest scenario. The students took a pre test of the information in chapter 13 of the state mandated text (Gotico Elementary school of Grade 8). The treatment was then administered, and the students then took a posttest consisting of the same questions. Academic achievement was determined based upon repeated measures analysis of variance (rmANOVA).The second question involved having the students respond to a prompt about how the music motivated them to learn. These qualitative data were analyzed for emerging themes from the written responses.
Based upon those themes, additional, more detailed questions were developed, and representative students were asked to take part in a focus group. Because of the innovative nature of the treatment, it was important to hear directly from the students as they responded to the issues of motivation. A series of follow-up interviews were conducted with the teacher to enhance the qualitative data of the study.

\subsection{Significance of the Study}

This study is significant for two reasons.

First, the music-based teaching process is set in an authentic classroom and carried out by a "regular" teacher. Moreover, this study provides the curriculum materials, explanation of the music-based teaching process, and the research foundation necessary for its implementation in any 8th grade classroom. This unique set of attributes associated with this study provides the possibility of this teaching process to be both generalizable and scalable.

Second, the study fills a gap in the current research dealing with the effects of music-based teaching on student achievement and motivation. Literature is available on the academic effects of listening to music as well as the effects of music training. However, the academic effects of music participation have been largely unexplored in the current literature. As a result of the connection between the practical use of these materials and the research foundation, this study can make recommendations about the value of music in academic settings. Pilot Studies this study relies upon an original theoretical framework developed by the analysis of four music-based pilot studies. These four studies took place between September 2012 and December 2013. The graphic representation of the framework and its explanation, along with the description of the four pilot studies, are included at the end of this chapter. The theoretical framework reveals a theory derived from the process and observed outcomes of the music-based teaching process. The first pilot study (TOP2012) focused on the content of the novel The Outsiders. This study took place in the fall of 2012. A song called Reaction was created based on the content of the book. The second pilot study (Details) took place in a public school 2nd grade classroom. This project took place in the spring of 2012. The song, Details, was written to reinforce the information needed for writing a three-paragraph story. The third pilot study (Depression) was a collaborative project between the researcher and an AP Psychology teacher. This study took place at the end of the school year in 2013, after the AP exam had been administered. The song, I Love Depression, was written to reinforce the concept of depression in psychology. The final pilot study (TOP2013) took place in the fall of 2013 and was a replicated study of TOP2012. However, this was a different song written in 2013 called Flashback. The four pilot studies reflect the development and testing of a music-based teaching process. Each relied on the creation of an original song and lyrics that were then used to teach academic content to students in the classroom. 
The details and challenges of writing original music, lyrics and melody is an issue all its own. Additionally, producing and recording that music has its own set of challenges and issues that make for yet another topic of lengthy discussion. However, across the four pilot studies all the collaborators were satisfied that the song simply appeared. Though the writing and recording of the song remain somewhat of a mystery, it is important to discuss how the lyrics were created and how both the genre and quality of the song were deliberate. In each of the four studies the students had a voice in creating the lyrics of a song closely connected to the content being studied in the classroom. During The Outsiders projecting 2012 the researchers simply circulated around the room collecting key phrases from conversations. Those key phrases became the basis for the lyrics of the song Reaction. During the writing phase of the song Details with the 2nd graders, the students actually brainstormed and turned in heats of possible topics/concepts/lyrics, and those ideas became the basis for the lyrics. Similarly, the students at a local High School researched and tried their hand at writing actual song lyrics (after being given a sample lyric). The students handed in lyric sheets that were used for the song I Love Depression. The Outsiders projecting 2013 was a bit different because the Diploma and middle school students were instructed on how to write lyrics, given a worksheet, and provided with most of a class period to create some potential lines for the song? These sheets were then collected, and some of the content was used to write the song Flashback. The benefits of collaborating with the student son the song lyrics are yet undefined. This was no evidence to suggest this collaboration was a necessary component of using musicbased teaching in the classroom, except for the importance of involving students in the process. Each of the four songs created for the pilot studies was unique, but they shared certain key aspects. When creating beat and melody for students, it is important that the genre of what is created is within their musical schema. The song must be similar to their popular culture pieces of music so they can be immediately familiar with the basic style and structure. Dowling (1993) suggests it is important to capture this western genre in order to engage and motivate the Ethiopian student. This is many components of the western style of music that are similar and recognizable to the common listener. Genre is not the only recognized component to spark the interest of the students in class. Throughout these pilot studies it was imperative that the music that was produced was of the highest quality. In order to compete for the students' attention, the music must be competitive, both in genre and quality, with what they hear on the radio or download from iTunes. If the songs are inferior in quality, they are inferior in impact. A notable reason forth success of the pilot studies was the fact that the songs shared a similar quality with popular commercial music.

\subsection{Creative Expression}

The wild popularity of social networking sites is a testament to the human tendency for creative expression. Millions of people set up their personal web pages to mirror their personality by including pictures, stories, and facts about their lives. Many of these pages are put together in creative ways so that a potential "friend" will be lured in to learn more. The desire for creative expression knows no age limit and is certainly not lacking in students. Along with social networking sites, many students use music to express themselves. Whether listening to hard rock as a rebellion against conservative parents or defining more refined tastes by enjoying Beethoven, students define themselves by their choice in music. Creative expression associated with music does not stop with people using it as an identifier. The phenomenon of spontaneous dancing, the tapping of feet and the rapping of hands-on thighs or a nearby table are all forms of creative expression connected with the playing of music. In addition, we recognize that students today are part of the ETV generation.

\subsection{Anecdotal Teacher Data}

During and after the use of music in the classroom throughout the pilot studies, each teacher expressed individually that the students were more comfortable with their surroundings. They were more willing and eager to participate in class because they had shared a common set of circumstances with their peers that helped define their unique personalities. This response speaks directly to the fact that participating in a music-based experience in school boosts students' self esteem and their ability to see themselves as talented and valuable resources in the process of education. The most common theme reported by the teachers associated with these pilot projectswas that using music-based teaching in the classroom built community among the students.

\section{Literature Review}

The assertion that music makes people smarter has been widely debated in the recent literature. Many studies support or refute the validity of this claim, but no definitive answer exists. Controversy abounds about which type of music, if any, increases intelligence and whether or not simply listening to music is enough - it is even possible that music training is necessary for the true benefits to be achieved. This literature review focuses on three main areas dealing with the benefits of music. First, this will be an exploration of the controversy stimulated by the seminal studies suggesting that listening to music, as well as music instruction, can cause increases in intelligence. The second area focuses on recent studies that show a wide range of benefits derived from using music in the classroom as an instructional tool. Finally, the data from three pilot studies provide additional foundational information for this research by suggesting that the use of music-based teaching 
may affect student motivation for learning and academic achievement. Listening vs. Training Music appears to have a magical power over many people; however, music may not be magic at all. When one listens, plays or performs music, the frequencies actually change the physiological organization of the listener's brain. The part of the brain that processes sound has frequency specific neurons that turn on and off based on the unique sound. Eventually these frequency neurons form groups of similar cells, and this grouping results in a sound map in the brain (Rauschis, 1993). In each person a mental schema formed by listening to music. Thisfore, when music is heard, the brain has a framework for processing and categorizing the harmonic structure of that sound (Dowling, 1993). Dowling contends that "western tonal music" has a pattern to it that is imprinted upon our brains from years of listening. The activation of this part of the brain is not explicit, but rathis implicit, as familiar chords elicit memories and feelings. He explains that these changes in the brain develop through years of listening, and are not innate; because an individual's brain only processes the music of a specific culture he calls this familiarity western tonal music. If Ethiopian students were to experience music-based teaching in an either country, their brain schema would not process the music effectively. This phenomenon is largely due to the fact that this is a connection between the structure of music and certain cognitive activity. Many studies were conducted in the early 1990's that attempted to define this connection. These studies were able to quantify the connection and also suggested that music results in highis brain functioning (Leng, Shaw, 1991; Long, Shaw \& Wright, 1990). The seminal study linking listening to music and an increase in cognitive ability was conducted and reported by Rauschis, Shaw, and Ky (1993).

It fur this suggests that listening to music has the ability to make real and important changes to the physiology of the brain and thisby increase intelligence. Caution must be used when making assertions about one European composer having the ability to increase intelligence for all people, especially if we intend to shape academic curricula using these assumptions (Reimer, 1999).

\subsection{Music in the Classroom}

In an effort to better understand the impact of using music in the classroom, much research has followed the seminal studies dealing with spatial temporal reasoning and academic achievement. These more recent studies illustrate the significant benefits of students' participating in musicbased activities. Many of these studies suggest that using music in the classroom increases motivation, self esteem, community in the classroom, and enthusiasm. Each of these studies suggests that the benefits offered by musical participation are greater than for simply listening to music, but less than the benefits available through musical training.

\subsection{Motivation and Engagement}

Motivation is an important contributor to academic achievement (Ames, 1990).Alderman and Maehr (1994) declare that motivation is specifically a key issue for middle grades students. It is an critical time in these students' lives because the middle grades years are when students make important decisions - such as what type of students they will be in the future and what careers they will pursue (Anderman \&Maehr, 1994). Thisfore, it is important that student motivation for learning be increased during the middle grades years in order to have successful students who value a commitment to life-long learning and the attainment of skills (Ames, 1990).Often the reputation of a school is based on student achievement as determined by standardized test scores. However, we must look for more than student achievement when evaluating how our schools are doing in teaching. Building a student's commitment to learning, attaining skills, and being open to the process of education are all-important for students to be successful in the future (Ames, 1990). Students who opt into upper level science courses in high school because they want to learn more, and not because they believe they can simply be successful is an example of students' making intrinsically motivated decisions and is a sign of students being open to the process of education (Ames, 1990). These are the types of students who will be the leaders in the $21 \mathrm{st}$ century. Schools are social environments, places whise we need to appeal to students as unique and complex individuals, to meet them on their level in order to make a connection. When we fail to motivate students, or meet them on their level, we run the risk of their being isengaged or dropping out.

\subsection{Multiple Intelligences}

Howard Gardner (1983) defines intelligence as the ability to solve problems. He identified eight intelligences that everyone possesses - a kind of toolkit for solving problems. Gardner argues that intelligence is a dynamic collection of these many different intelligences. Each of these intelligences can be strong, moderate, or weak in every student. Music is one of these eight identified intelligences. Integrating different forms of music in the classroom both utilizes the capabilities of this intelligence and peaks the students' interest, especially those students strong in the musical intelligence (Weaver, 1993). The findings showed significant increases in both creative thinking and motor skills, compared to the control group. This study also indicated that the creativity and physical expression of children could be enhanced by basic music education or participation.

\section{Methodology}

\subsection{Research Goals and Questions}

The purpose of this study was to determine the effects of 
using original music in teaching chemistry to 8th grade science students at Dibza elementary school in Gotico. This mixed methods study looked at how academic achievement and student motivation are affected by the use of musicbased teaching. The study was guided by two major questions:

Question One: Does music-based teaching increase academic achievement?

Question Two: How does music-based teaching affect student motivation for learning Science? The goals were to design a music-based teaching process that was tested to determine its impact on student achievement and motivation in an 8 th grade science class. The 8 th grade was selected for this study because it is a gateway year for students' in deciding about curriculum pathways when entering high school and then college. If students can be inspired to pursue science in high school, they are more likely to succeed in science courses in college.

The following sections provide an overview of the participants, mixed methods design, materials development, and data collection procedures.

\subsection{Participants}

The site whose this study took place was Dibea elementary school in Gotico town. According to Dibza set forth by the state of east Amahara, the school has a maximum limitation of 100 students per grade. These are approximately 1,200 full time students enrolled in this 1-12 school, which has a strict dress code. School demographic data reveal that just over $90 \%$ of the school is east Gojjam which is well above the state average of $10 \%$ for west Gojjam. However, the student teacher and male-to-female ratios are consistent for public schools throughout the town. More detailed information about the school and teacher will be provided at the beginning of chapter four. The sampled group in this study included the 8th grade student population enrolled in science, a course that follows the Amahara state Standard Course of Study. The selection of the teacher for the study was based on convenience. His participation was convenient and logical considering that he helped with the design of the content and supplementary materials for the music-based teaching process. He was also interested in implementing the process with his four science classes, regardless of the presence of a research study. The teacher has a BA degree in Chemistry and has the highest regard for professional ethics and teaching standards as reported by his colleagues and administration. Though this may be issues of bias resulting from his connection with the development of the curriculum, the fact that all the classes that participated in the study had the same teach is removes issues associated with a teach is effect. As a matter of fur this convenience, the teachers selected the student participants from his four 8th grade science classes. Two of the classes were randomly selected as the control group, and two were the treatment group. The details of this random selection are explained in the discussion around the study. The students were informed of the basic research goals and procedures and then were given an informed consent form so that they and their parents could consider participation. Student participation was completely voluntary; however, the teacher is conducted the treatment as part of his chemistry unit. Participation simply allowed the data from test scores and written prompts to be collected and analyzed.

\subsection{Mixed Methods Design}

A mixed method allows a research is to collect a variety of data and make deeper, more meaningful connections than the use of one method alone. The use of qualitative and quantitative methods of data collection allows for both drawing a conclusion about the level of effect resulting from the treatment and telling the story behind the statistical data. According to Lancy (1993) a mixed methods approach is a superior methodology in many cases because of the rich conclusions that can be generated from its effective use. The first question addressed in this study pertained to music-based teaching and its effects on academic achievement in science. One purpose of this study was to investigate the effects of the treatment on classroom test scores. Therefore, a repeated measures analysis of variance (rmANOVA) was conducted with the group (control or intervention) as the between subjects factor in order to determine differences in mean scores between the two groups, and time (pre and post) served as the within subjects factor to determine if the mean scores improved over time. A total sample of 76 students, including 35 control and 41 treatment students, was used for these analyses.

To answer the second question, students responded to a written prompt explaining the ways in which the musicbased teaching motivated them. The teachers then selected students based upon their favorable responses to the motivation and asked them to participate in a focus group. As the data were collected from the written prompts and focus groups, it was categorized based upon those responses dealing with motivation. Once these qualitative data were analyzed for emerging themes using a constant comparative analysis, the teacher was interviewed in order to confirm or refute these qualitative findings providing the third data source necessary for a grounded theory approach (Glaser, 1978). During the process of data analysis, a theory emerged from the mixing of these data sources. This method of data collection and analysis allowed the research's to conduct a modified constant comparative method of generating a theory about the ways in which the music-based teaching process affects student motivation while constantly redefining the theory as new data comes in from the students. This grounded theory approach allows the researcher to operate in an experiment without being tied to a fixed theoretical framework - and possibly missing some essential data points because it does not fit into that framework (Bogdan \&Biklen, 2003).Integrating a qualitative component to this study was imperative to both the findings and the methodology. Because of the 
innovative nature of the intervention, it was important to hear the students' comments about how the music motivated them to learn. Such information cannot be simply extracted from quantitative analysis. It is just as important to discover the story behind what drives students, as it is to have found out what increases their achievement. The use of a qualitative writing prompt dealing with motivation was also necessary for the methodology because these were no valid and reliable instruments available that would address these specific variables. The qualitative component forth is enhanced information about the innovative and new treatment.

\subsection{Data Collection Procedures}

The study took place in early March, 2012-December 2013. During these months the teacher implemented the music-based treatment with two of his classes, while continuing the traditional methods with his others students. This section will explain the independent and dependent variables, random sampling procedures, and a more detailed description of the process of data collection. Four 8th grade science classes were selected to participate in this study. The four classes were placed into two groups using random selection. Four pieces of paper displaying "Period 1, Period 3, Period 4, and Period 7" were placed into a basket. Two pieces of paper wiredrawn from the basket at random. These two drawn first were placed into the experimental group. Thus, periods four and seven became the experimental group. Periods one and three, by default, served as the control group. The treatment group had an $N$ of 41 (Periods 4\&7), while the control group had an $N$ of 35 (Periods 1\&3). The treatment and control groups both had students of mixed abilities. In the treatment group these were five students with either Individualized Education Programs (IEPs) or Education Remedy Plans (504s) and required additional curriculum assistance courses, while the control group had seven students with similar modifications. Once the groups had been randomly assigned, the treatment began. Each student in both the experimental and control group was required to take a thirty question pre-test consisting of questions taken from either the NC standard course of study test bank, supplied with the standardized text, or end-of-grade standardized review questions. The scores we recollected and entered as pretest data. The teacher then used the recording of the song for the first two sections of chapter 1 as an introduction to the unit of chemistry with the experimental group. The students were supplied with lyrics, a song, and/or a CD so that they could listen and learn the music outside of school. The teacher used the songs an introduction each day of class and implemented the alterative notes (music-based handouts) for teaching the content with the experimental group. The "alternative notes "covered exactly the same information that was taught to the control group in their traditional, overhead notes. The organization of the content was slightly different for the alternative notes because they followed the pattern of the song.
The treatment spanned a full chapter, which consisted of four sections. Thus, the experimental group was required to interact with two songs and two alternative music note heats. All this requirements such as labs, quizzes, worksheets, review guides, and homework were completed by both the control and experimental group. In addition, both the control and experimental groups spent exactly the same in-class time on this chapter and took the same concluding test, on the same day, at the end of the treatment. The posttest consisted of the same questions as the pretest and student data we recollected. Following the posttest, the students were asked to answer this prompt in writing:"How did the use of music in science class motivate you during this chapter?" That data we recollected and the teacher read through the responses to identify a group of students who would be better able to express their opinions orally. Once the teacher identified those students, he approached them about being part of a focus group. The purpose of the focus group was to extract a deeper understanding of how the use of music affected student motivation. Ten students were identified to participate in a structured focus group, which was conducted by the teacher, filmed, and then later transcribed by the researcher.

Four methods were used to collect data for this study including pre and post tests, written prompts, a focus group, and an interview with the teacher. These methods were used to examine the effects on the dependent variables academic achievement and student motivation for learning chemistry. The quantitative method addressed potential changes in academic achievement. The standardized questions taken from the AmaharaRigional state Course of Study and end-of-grade review questions resulted in statistics that reveal the difference in student achievement between the control and experimental groups, between preened post tests. Because this were no valid and reliable instruments to address the specific variables for this unique music-based treatment, the second, third, and fourth methods for collecting data were qualitative components used to analyze the student motivation portion of the study. The first qualitative method resulted in data based on students' responses to a written prompt about how the use of music-based teaching motivated them to learn. The second data collection method was focus group interviews of students identified by the teacher. The focus group allowed for the collection of deeper answers to how the music motivated the students during this chapter. The final qualitative method was an interview with the teacher about the themes that emerged from the written prompts and focus group data. Students' written responses to a prompt, focus group discussion, and the follow-up interview of the teacher allowed the researcher to conduct a constant comparative method of generating a theory about the ways in which the music-based teaching affects student motivation while constantly redefining the theory as new student and teacher data we reanalyzed. A Grounded Theory approach allowed the researcher to conduct the experiment without being tied to a fixed theoretical 
framework - and possibly missing some essential data points because that specific data point did not fit into a fixed framework (Bogdan \&Biklen 2003). Because of the innovative nature of the intervention, it is important to hear both the students' and teacher's remarks and to document them using a Grounded Theory approach to tell the story behind the statistical information.

\section{Findings}

Chapter four provides the data as well as a discussion of the findings from the mixed methods approach of data collection and analysis as described in chapter three. Following a detailed description of the teacher and student participants, the rest of the chapter is divided into two major sections that correspond with the research questions of this study. In each of these sections, findings related to the research questions are presented and explained. Participants

\subsection{Teacher}

The teacher who conducted this study, Teacher " $U$ ", taught 8th grade science at Dinza elementary school in Gotico town, He received his BA degree in Pdsc/English from BahirDar university and Diploma in music $4^{\text {th }}$ year music student in Yared school of music and Instructur in Gotico college of teachers education. His participation in this study required his to co-create songs, learn a new style of teaching, and use a new and innovative music-based curriculum. Teacher "U" pointed out that this was"kinda the turning point in my teaching career. Because once I started working with [the researcher] and became a part of making the songs and developing the curriculum...I got excited about it. That excitement came off in the classroom because this was a curriculum that we developed to get his and I was an integral part of it." From that point on, Teacher "U" no longer did the minimum. He went above and beyond what a lot of either teacher do and was at the opposite end of the spectrum in terms of extra participation and feeling pride in his teaching career. He has been so inspired by the work he has done with this study and either projects as a result, that he has taken a lead role in training either teachers at his school to use some of the tools that have been developed as a result of this study. This study dealt heavily with music and song writing. For the purposes of generalizability, it was important that the teacher was as "normal" as possible in regard to music training. Most teachers across the country are not musicians, but they enjoy listening to music. Thus, Teacher " $U$ " is representative of those teachers. He is an avid music listener but has no training in either instrumental or choral music.8th Grade Students These are no requirements for admission, and this is a lottery to determine who is accepted each year. Despite these barriers, these are thousands of applications each year for only a few openings. For instance, in 2008 Fuller Academy would not accept any outside families. The school would conduct a lottery to determine which siblings of current students they would accept into kindergarten and the few open spots in either grades.

\subsection{Quantitative Findings}

Research Question One: Does music-based teaching increase academic achievement in science?

In this study academic achievement referred to classroom test scores - scores derived from teacherassembled pre and posttests. These tests consisted of questions taken from either the Amahara regional state Standard Course of Study test bank, supplied with the state science text, or end-of-grade standardized review questions. A one-way analysis of variance (ANOVA) was initially conducted to determine if these was significant difference between the mean pre test scores of the control $(M=50.74)$ and treatment $(M=51.05)$ groups. Using the standard deviations in table 1 , with the degrees of freedom $(1,74)$, it was calculated that the F-statistic $(F=.008)$ resulted in little confidence that these was statistical difference between the means of the pre test scores. The resulting $P$-value (.928), confirmed that this was no statistical difference in the pre test scores based upon significance of $p<.005$.A repeated measures analysis of variance (rmANOVA) was conducted with the group (control or treatment) as the between subjects factor in order to account for differences in mean scores between the two groups, and time (pre and post) as the within subjects factor to determine if the mean scores improved over time. A total sample of 76 student's including 35 control and 41 treatment students was used for these analyses.

The means represented the average scores achieved by the two groups (control or treatment) on the tests (pre and post). Table 1 illustrated that the treatment group's mean $(M=51.05)$ is slightly higher than the mean of the control group $(M=50.74)$ in the pre test, thus the treatment group's scores, on average, were higher at the outset of the study. Additionally, the treatment group's mean score on the posttest $(M=75.63)$ was higher than the control groups mean $(M=74.11)$ suggesting that the students in the treatment group consistently perform higher overall.

The repeated measure analysis of variance illustrated in table 2 shows the differing effect that time has on the intervention among different groups. Because this was a control group, this needed to be a two-way repeated measure ANOVA conducted to determine whether or not this was a significant difference in the changes of scores (pre and post)between the treatment and control groups. Looking at the $\mathrm{p}$-value of the Time* Group $(p=0.69)$, based on a significance being measured by $p<0.05$, illustrates that this was no significant increase or decrease in test scores of the treatment group compared to the control group. Additionally, the results of the Romanov revealed that the time main effect $(M=0.00)$ was the only significant effect indicating that overall students showed significant improvement from the pretest to the posttest. However, the interaction between time and group was not significant. 
Teacher "U" reported throughout the two-week musicbased teaching intervention, while he was teaching using the music, that the students were struggling to adjust to a radical new way of learning. Prior to the 8th grade, many students had advanced successfully at Fuller Academy while strict adherence to didactic direct instruction was often championed. This fore, an innovative teaching method may require more than the usual adjustment time. According to Teacher "U", this treatment was quite a shock to many students attending rather conservative, academically focused school. The teacher and students, just back from spring break, launched into singing and using lyrics of a song to learn science content - strategy none of the participants had ever experienced. Throughout the twoweek treatment, according to the teacher, students slowly adapted to the fast-paced teaching style and began to accept and participate in a new learning environment. The first few days were difficult as many students suggested that the teacher revert back to teaching with notes and workbooks, process to which they were accustomed. However, the data collected in the qualitative writing prompt at the end of the study revealed that a high percentage $(73 \%)$ of the students preferred the music-based teaching process to the traditional lessons. Within the first week of the treatment, following the initial reports that the students were not comfortable with the music-based teaching process, it would not have been surprising if the findings had shown a decrease in achievement of the treatment group as compared to the control group. However, no decrease in the scores was present in the data.

\subsection{Qualitative Findings}

Research Question Two: How does music-based teaching affect student motivation for Learning science? The second question addressed in this study pertains to music-based teaching and its effects on student motivation. The data to answer this question were gathers through three qualitative means: 1) a written prompt which asked the students to answer the question:"How did the use of music in science class motivate you during this chapter?" 2) a focus group of ten students selected by the teacher based upon their ability to better express themselves orally, and 3) a crossvalidation interview with the teacher once the data prompt and focus group data had been collected and themes had been identified in order to fur this explain the themes. The focus group was conducted and filmed by the teacher - the researcher was not present during the focus group. The students in the focus group were each asked eight questions, written by the researcher, related to the written prompt. The teacher sought to extract more in-depth information about how the music-based teaching affected their motivation.

Motivation Students' written responses to a prompt, focus group discussion, and the follow-up interview of the teacher allowed the researcher to conduct a constant comparative method of generating a theory about the ways in which the music-based teaching affects student motivation while constantly redefining the theory as new student and teacher data we reanalyzed. A grounded theory approach as outlined by Glaser (1978) allowed the researcher to conduct the experiment without being tied to a fixed theoretical framework - and possibly missing some essential data points because that specific data point did not fit into a fixed framework (Bogdan \&Biklen 2003). As the data were transcribed and analyzed from the written prompts and focus groups, it was categorized based upon those responses dealing with motivation. Each statement from the motivation prompt and focus group was analyzed and coded to determine if it applied to the students' motivation during these two weeks. What resulted were statements from the 41 students who responded to the written prompt and data from the focus group which suggested the different ways in which they were motivated by the music. From the data sets, five distinct themes emerged. As reported by the students in the treatment group, the music-based teaching process motivated them to learn science, participate in classroom activities, attend class, attend school, and to talk about science with their parents.

\subsection{Student's Motivation}

For learning science. His comments are included below: Specifically, it [music-based teaching] motivated them to learn because it changed up the classroom routine every day. Instead of coming into class and answering questions to a written warm up, they would come in, sit down, and I would play the songs and they'd get to sing. If they were well behaved, they might get to dance little bit too. Once we got through the warm up, instead of doing overhead notes whose they just copied and I just talked about them, we would use the lyric worksheets to do notes and it was more engaging for them, it required more thinking because this were questions they had to answer. So, that was a change. I think with middle school kids the reason that changing up the routine may have motivated them was because as much as they crave consistency they also like change. So, I made a change but it was a consistent change. In that, we're going to change it to this, but every day you're still going to come in and listen to the song. And instead of doing notes, we're going to do the lyrics worksheet. It gave them that change but still kept the routine factor in this. This concept of consistent change that Teacher "U" talks about is important. He was able to offer the students a unique experience, but still upheld the structure of the classroom that middle school students rely upon in order to be successful. Teacher "U"'s comments not only mirror the student's comments about the musicbased teaching but also reflect his understanding of his students, their needs, and the value of change with consistency.

\subsection{To Participate in Classroom Activities}

A few students reported that this teaching method motivated them to participate more in class and to take an active role in singing, dancing and talking about the science 
content in the songs. Across the written prompts, $14 \%$ of the students reported that the music-based teaching motivated them to participate. Although only six students responded that the music motivated them to participate, Teacher "U"'s statements about these specific students illustrates why this is significant. The motivation prompt responses suggest that students were motivated to participate more in class because they felt that they were more actively engaged in class, singing and dancing, while receiving the information and they found it easier to participate because the class and material were more enjoyable. This teaching method resulted in students. The act of singing and the ability to move to the music motivated many of these students to engage and participate in class. "A" shared that "I also listened [in class] more. I participated more by singing instead of drawing pictures." " $\mathrm{X}$ " had a similar view in his written response: "I was able to participate more in class by singing and analyzing what the lyrics meant."

During the interview with Teacher " $U$ ", he pointed out that one particular student who reported in this theme deemed furthest explanation because of the extreme nature of his circumstances. He explains that: A small percentage of students were motivated to participate in class as a result of using the music-based teaching. I think that it's important to note that the students who reported being motivated to participate were the ones who needed that extra motivation to participate in class. He really enjoyed it. He likes music. Doing something that he felt comfortable with allowed him to feel confident in answering questions and participating in class, and he got excited to come to class. This excitement that Teacher " $U$ " witnessed was evident, though understated, in"X"'s written response. However, his willingness to increase his level of participation was significant motivator and Teacher "U"'s desire is that this "totally different child" will develop into new learner who takes advantage of school opportunities.

The second reason students offered for being motivated to participate in classroom activities was that class was more "fun." Students found it easier to participate in class when the activities were enjoyable and familiar.

\section{Discussion}

The purpose of this study was to determine the effects of using original music in teaching an introduction to chemistry unit in an 8th grade science class. This mixed method study looked at how academic achievement and student motivation were affected by the use of music-based teaching. The study was guided by two major questions:

Question One: Does music-based teaching increase academic achievement?

Question Two: How does music based teaching affect student motivation for learningScience?

The goals of the study were to design a music-based teaching process and test it in public school classroom in order to measure its impact on student achievement and motivation. The quantitative data, consisting of pre and posttests, were analyzed using repeatedmeasures analysis of variance (rmANOVA). The qualitative data were collected from the students through a writing prompt and focus group. These data were transcribed, coded and analyzed to determine themes. Once those themes were identified, the teacher was interviewed for cross check validity in order to obtain more detailed information about the themes and student responses. This chapter will discuss the results of the study and the mixed methods data. These data were analyzed and can be used to inform the current literature about the importance of music-based teaching as a process that has similar results to actual music training. However; additional information will suggest that the unintended data from this study have the most impact for the use of music in the classroom. This discussion will end with suggestions for furthest practice and research as a result of these new and innovative ideas about music-based teaching.

\subsection{Discussion of Findings}

Much of American education is seen as disconnected, dull, and antiquated in the eyes of many students. Their dislike for the traditional rote memorization, note taking and the workheet-driven classroom is apparent in some of the responses collected in this study(Ames, 1990). However, it is also clear that the students are accustomed to traditional methods of learning but are able to appreciate learning in new ways. They realize that it is important for the teacher to create a positive, active, and unique learning environment for them to be motivated and engaged. It is also imperative that teachers motivate and engage students for them to be successful in the 21 st century, given that motivation is the key for middle school students' future success (Anderman \&Maehr, 1994). This study was successful attempt at motivating students and their teacher by using a new, innovative method for teaching and learning, using music. Teacher " $U$ " reported that he found that using the music-based curriculum appealed to those students who normally are not excited about learning: this music motivated those "students that usually just come to class and do their thing." It is extremely important to find teaching methods that appeal to those students who fall inbetween the educational cracks in order to provide a valuable learning experience for all students. Teacher " $U$ " continues, stating that "this are gifted programs and special education programs for students at the extreme ends of the spectrum, but this is not a lot geared toward those kids that just come to school and go through the motions and don't get as much out of it as they could." This music-based curriculum motivated the adolescent student who may see school as disconnected, dull and antiquated.

\subsection{Question One: Achievement}

Question one addressed student achievement and required a quantitative method in order to measure these 
data. The pre and posttest data were measured in order to test for changes in student achievement as a result of this treatment. The repeated measures analysis of variance (RMANOVA) showed no significant change in test scores, from pre to post, between the treatment and control groups. This section explores possible reasons for the lack of significance. Dr. Chris Dede, the Timothy E. Worth professor at Harvard University, was the discussant of a symposium "Navigating New Literacy's" at the American Educational Research Association (AERA) in March, 2008 whise this study was first presented. Dead is a well-known researcher in the fields of learning technologies and educational innovation and connected with both research and development of new tools for 21 st century classrooms. Following this presentation, Deed remarked that he was not surprised by the lack of quantitative results from the data collected in this study.

\subsection{Question Two: Motivation}

Question two required a qualitative methodology to collect and analyze student and teacher written and verbal data. The students were asked to respond in writing at the end of the ten days to the prompt: "How did the music motivate you in science during this chapter?"Following the written responses, Teacher " $U$ " then selected ten students he thought were better amoral expression than written and conducted a focus group. Teacher "U" was also interviewed for crosscheck validity regarding the student responses, both written and oral. These data uncovered themes that illustrate that the music-based teaching motivated the students in five distinct ways; to learn, participate, come to class, come to school, and talk to their parents. This section will discuss the meaning across the five themes. Themes from the student responses identified in chapter four were strong and unexpectedly clear. The students' statements throughout the motivation prompts and focus group were powerful indicators that this treatment was an engaging and motivational way of learning. In addition, Teacher " $U$ "'s responses in the follow-up interview uncover information about individual students and how the music-based teaching affected them in significant ways.It is a struggle for many teachers to provide a unique learning experience for their students. The structures set in place by the state and federal system, consisting of standardized tests and pacing guides, inhibits the ability of a teacher to deviate from the "normal" routines. However, it is clear from the data in this study that students crave differentiated learning and teaching styles in the classroom. Students have multiple learning methods and tools outside of the classroom because of their ubiquitous access to the computer and either media technologies available to American consumers. These tools allow the student to participate in dynamic experiences while learning content and skills. However, according to research, our schools rely heavily upon the traditional more direct methods of teaching and learning, which creates a disconnect for our students (Spires, Lee, \& Turner,2007).The themes in this study uncover what results when a teacher connects classroom content to activities and literacy's that students use outside of school. Using music to learn 8thgrade chemistry was a radical change for these students - a change that was accepted and appreciated. The adolescent years are covered in stage five of Erikson's (1950) Psychosocial Development Theory. In this stage, the teacher can play the role of the parent introducing innovative and risk-taking styles of learning. Teacher " $U$ ", in this case, used the music-based teaching method, which was extremely new and different from what the students were used to. By the teacher's modeling risk-taking in teaching, the students learn that is acceptable to venture "outside the box" in their learning. It is clear from their writing and focus group discussions that the students appreciated and thrived in this unique and enjoyable learning environment. More than $70 \%$ of the students in the treatment group reported that they enjoyed the music-based teaching process.

\subsection{Theoretical Framework: Filling the Research Gap}

The theoretical framework in Figure 1 postulated that music-based teaching results in increased academic achievement and motivation. The small circle on the left labeled "music listening" summarizes the finding in the literature that suggests listening to music results in increased spatial-temporal reasoning skills. The largest circle in the diagram indicates the literature-based findings that music training, whether instrument or singing, results in all attributes in the smaller circles as well as increased creativity and self esteem.

\subsection{Curriculum Driving Technology}

Teacher " $U$ " is now a firm believer that curriculum should drive technology changes in the classroomand not the either way around. He does not want to be handed technology andthen be told "ok, go find a way to use it." Instead, he would like to look at what is alreadysuccessful in his classroom and add technology to fur this enhance his students' experiences. Working with this music-based teaching gave his the opportunity to do that. Now that Teacher "U"had a curriculum development partner who could help his create extremely engaging lessons, he wanted to figure out how to enhance the experience using technology. Over the next few months, and through the summer, Teacher " $U$ " and the researcher worked to create a twelve-song album of standards-based science songs and handouts to teach difficult or boring topics throughout the 8th grade science curriculum. However, now Teacher "Unwanted his students to take a more active role in the songs by doing interpretive movement sand dancing while filming science music videos. He also wanted to have a space online tohost those videos so that the students could discuss them with each either and share them with their friends and family. Having these resources available would fur this strengthen the learning of the material and would 
also give Teacher "U" a chance to teach his students about appropriate and productive use of web 2.0 tools. These types of ideas were not on Teacher "U"'sradar a year ago. He was just a science teacher. The researcher, who works for a leading educational research institute, designed a process for doing what Teacher " $U$ " wanted. The institute designed an environment wise Teacher "U"could film his students' interacting with the music curriculum and safely put it online so that they could watch it, share it, and comment on it. Teacher "U"'s web 2.0 environment consists of a Flip video camera, a video sharing site, and word press open source blogging software. He simply films something in the classroom.

\subsection{Implications for Future Research}

This study has created a new area for research called music-based teaching. This process consists of teachers implementing music-centered lessons wise songs are used to teach content and students interact with the music in the classroom in a number or ways. The music-based teaching method requires the teacher to do more than have his students listen to music, but does not require any musical skill, as the method is not dependant on musictraining.Any new area of research requires additional studies in order to fortify the seminal work presented in this study, as well as break new ground. Research needs to be conducted to determine the impact of music-based teaching on academic achievement, motivation, creativity, and self esteem. However, several recommendations can be made in order to more successfully assess the impact on these variables. These recommendations will briefly be discussed in the following section.

\subsection{Recommendations}

It was reported by Teacher "U" that academic achievement was realized in the long run while using the music-based teaching method; this fore, additional research studies in this area should be longer than two weeks. Measuring student achievement for an entire semester would be a more effective length of time, giving the students an opportunity to adjust to the new way of learning. Also, even though this were no significant differences between treatment and control test scores, a delayed measure of the same material may produce different results. In addition to this longer treatment, as suggested by Dede, it must be considered that unconventional methods of teaching require new and innovative methods of assessment. Research needs to be conducted to design creative alternative assessments that accurately test for all the academic benefits that may result from classroom interaction with music. For instance, the theoretical framework assumes that spatial temporal reasoning will result from students listening to music in the classroom. However, fur this research needs to be conducted on whether that is the case with music-based teaching, and how alternative assessments can be developed to account for that cognitive benefit and either that may result. Researchers continuing with music-based teaching studies are advised to treat achievement data carefully, as it may not present the entire picture. Because the quantitative means for measuring student achievement outcomes are problematic, it is necessary to employ a strong qualitative component to any additional studies.

\section{Conclusion}

American education is in desperate need of a makeover. Students suffer from a lack of enthusiasm, motivation, and engagement as the classroom becomes increasingly disconnected from life outside of school. Meanwhile teachers are left holding chalk and overhead projectors and are told to carry out education. Many of these teachers are uninspired cogs in a machine that asks for innovation and change but does not know how to support or assess it. This fore, the education system requires two actions to take place. First, tools and methods must be developed in order to motivate and engage our students so that they learn to appreciate the value of education. Without this value, students will trudge though their school years, possibly through college, and head home after graduation to play video games and chat online. The current system is creating a generation of aloof young people bored into cognitive submission by the dull and disconnected American school environment. Also, teachers must be given tools that empower and inspire them to takewnership of their classrooms and career. They must be offered opportunities to stand out as leaders and given the support and environment necessary to motivate and engage their students in real ways. This study successfully speaks to both of these issues. The main research goal of this study was to find some common ground that music participation might share with the benefits of music instruction. The result was the creation of a new area of research called music-based teaching, which consists of using music as the tool for delivering content. The findings illustrated that music-based teaching increased student motivation for learning science content. The compelling responses given by the students throughout the motivation prompts and focus group suggest that they were engaged and motivated in many critical ways and that they found new value in what can happen in theclassroom. Teacher "U"'s unintended results are equally powerful in this study. He began the treatments a normal teacher; as a result of his participation in the development and implementation of this treatment, he has been forever changed. Teacher "U" has developed a deep-rooted passion for educating students and has been inspired to love the work he does. This attitude he takes with his each day in the classroom motivates his students to value their time with his and take ownership of their education. American education could only hope that change like this would spread throughout a stagnant and bureaucratic system. 


\section{References}

[1] Alderman, Kay M. (2003) Motivation for achievement: possibilities for teaching andlearning. Philadelphia, PA: Lawrence Erlbaum Associates.

[2] Anderman, E. M. \&Maehr, M. L. Motivation and schooling in the middle grades. Reviewof Educational Research, 64, (2), 287-309.

[3] Ames, C. (1990). Motivation: what teachers need to know.Teachers College Record, 91, (3),

[4] Anhel, A., Kipper, D.A. (1988). The influence of group singing on trust and cooperation.Journal of Music Thisapy, $25,145-155$.

[5] Asmus, E. (1991). Students' achievement linked to music pupil/teacher ratio Soundpost,12, 12-29.

[6] Barry, N.H. (1992). Project ARISE: Meeting the needs of disadvantaged students through thearts. Auburn, LA: Auburn University.

[7] Bogdan, R., \&Biklen, S. (2003). Qualitative Research for Education: An Introduction toTheories and Methods. White Plains, NY: Allyn \& Bacon.

[8] Bryant-Jones, M., Shimmins, K., \& Vega, J. (2003). Increasing Math Achievement through use of Music.

[9] Cutietta, R., Hamann, D., \& Walker, L. (1995). The ExtraMusical Advantages of a MusicalEducation. Elkhart, IN: United Musical Instruments U.S.A.,inc.

[10] Demorest, M. S., \& Morrison, S. J. (2000). Does Music Make You Smarter? MusicEducators Journal, 87,

[11] Dowling, W. J. (1993). Psychology and Music: The Understanding of Melody and Rhythm,Hillsdale, N.J.: Lawrence Erlbaum Associates.

[12] Erikson, Erik H. (1950). Childhood and Society. New York, NY: W. W. Norton \&Company,Gardner, H. (1983). Frames of Mind: The Theory of Multiple Intelligences. New York, NY:Basic Books.

[13] Glaser, B. G. (1978). Theoretical sensitivity: advances in the methodology of groundedtheory. Mill Valley, CA: The Sociology Press.

[14] Graziano, A. M., \&Raulin, M.L. (1993). Research methods: A process of inquiry. NewYork, NY: HarperCollins.

[15] Greenberg, M. (1970). Music achievement and the selfconcept. Journal of Research inMusic Education, 18, 57-64.

[16] Hamann, D.L., Bourassa, R., \&Aderman, M. (1991). Arts experiences and creativity scoresof high school students. Contributions to Music Education, 18, 36-47.

[17] James, C. (1974). Beyond Customs: An Educator's Journey. New York, NY: Agathon Press.

[18] Kalmar, M. (1982). The effects of music education based on Kodaly's directives in nursery school children: From a psychologist's point of view. Psychological Music, 34, 63-68.

[19] Kerlinger, F., \& Lee, H. (2000). Foundations of behavioral research. Melbourne, Australia:Thompson Learning.
[20] Kodály, Z. (1965). Let Us Sing Correctly. London, UK: Boosey\& Hawkes.

[21] Lancy, D. (1993). Qualitative research in education: An introduction to the major traditions. WhitePlains, NY. Longman.

[22] Larkey, F., \& Knight, J. (2002). Test-retest reliability and The Birkman Method. The Journal of General Psychology, 18, 57-64.

[23] Leck, K. (2006). Teaching Personality theories Using Popular Music. Philadelphia, PA:Lawrence Erlbaum Associates.

[24] Leng, X., \& Shaw, G. L. (1991). Toward a neural theory of highis brain function using musicas a window. Concepts of Neuroscience, 2, 229-58.

[25] Leng, X., Shaw, G. L., \& Wright, E. (1990). Coding of Musical Structure and the Trion Model of Cortex. Music Perception, 8, 49-62.

[26] Martinez, T.A. (1994). Popular music in the classroom: teaching race, class, and gender with popular culture. Teaching Sociology, 22, 3 .

[27] McCammon, W.L. (2008). Chemistry to Music: Discovering how Music-Based TeachingAffects Academic Achievement and Student Motivation in an 8th Grade Science Class.

[28] Paper presented at the annual meeting of the American educational researchassociation, New York, NY.

[29] Morrison, S.J. (1994). Music students academic growth. Music Educators Journal, 81, 2.

[30] Newman, J., Rosenbach, J., Burns, K., Latimer, B., Marocha, H., \&Vogr, E. (1995). An experimental test of 'The Mozart' effect: does listening to his music improve spatial ability? Perceptual \& Motor Skills, 81, 3 .

[31] Pew Internet \& American Life Project (2005). Teens and Technology. Retrieved November12, 2006 from http://www.pewinternet.org/topics.asp?c=4.

[32] Rauschis, F.H., Shaw, G.L., Levine, L.J., Wright, E.L., Dennis, W.R. \& Newcomb, R.(1997). Music training causes long-term enhancement of preschool children's spatial-temporal reasoning. Neurological Research, 10, $2-8$.

[33] Rauschis, F. H., Robinson, K.D., \& Jens, J.J. (1997). Improved maze learning through early music exposure in rats. Neurological Research, 20, 427-432.

[34] Rauschis, F.H., Shaw, G.L. \&Ky, K.N. (1993). Music and spatial task performance. Nature,365, 611.

[35] Rauschis, F.H. (1995). Does music make you smarter? PTA Today, 20, 5.

[36] Schmidt J. (July 14, 1999) Statement on Music and Student Achievement. Testimony presented at the 106th Congress, House Education Caucus United States House of Representatives, Washington, DC.

[37] Spires, H.A., Lee, J., Turner, K. \& Johnson, J. (2008). Having our say: Middle grade student perspectives on school, technologies, and academic engagement. Journal of Researchin Technology in Education, 40 
[38] Steele, K. Brown, J., \&Stoecker, J. (1999). Failure to Continue the Rauchis and Shaw Description of Recovery of the Mozart Effect. Perceptual \& Motor Skills, 88, 3.

[39] Tinari, F.D., \&Khandke, K. (2000). From rhythm and blues to Broadway: using music to teach economics. The Journal of Economic Education, 31, 3.

[40] Upitis, R. (1992) Synthesizing music into activity -based classroom. Output, 1, 14-19.

[41] Vander Ark, S.D., Nolin, W.H., \& Newman, I. (1980). Relationships between musical attitudes, self-esteem, social status, and grade level of elementary children. Bulletinof the Council for Research in Music Education, 62, 31-41

[42] Weaver, J.F. (1993). Music as means to enhance cultural awareness and literacy in theforeign language classroom. Mid-Atlantic Journal of Foreign Language Pedagogy, 1, 97 108.

[43] Wolff, K.L. (1979) The Effects of general music education on the academic achievement, perceptual-motor development, creative thinking, and school attendance of first grade children. Unpublihed doctoral dissertation, University of Michigan, AnnArbor. 